\title{
Labour epidurals in Gauteng Province, South Africa
}

\author{
J Wagner, ${ }^{1} \mathrm{MB}$ BCh, DA, FCA (SA), MMed (Anaesth); S Chetty, ${ }^{2} \mathrm{MB}$ BCh, FCA (SA), Cert Crit Care, PhD; \\ F Paruk, ${ }^{3} \mathrm{MB}$ BCh, FCOG (SA), Cert Crit Care, PhD; P Kamerman, ${ }^{4,5}$ BSc (Hons); PhD \\ ${ }^{1}$ Department of Anaesthesiology, Faculty of Health Sciences, University of the Witwatersrand, Johannesburg, South Africa \\ ${ }^{2}$ Department of Anaesthesiology and Critical Care, Faculty of Health Sciences, Stellenbosch University, Cape Town, South Africa \\ ${ }^{3}$ Department of Critical Care, Faculty of Health Sciences, University of Pretoria, South Africa \\ ${ }^{4}$ School of Physiology, Faculty of Health Sciences, University of the Witwatersrand, Johannesburg, South Africa \\ ${ }^{5}$ School of Pharmacy and Biomedical Sciences, Curtin University, Perth, Australia
}

Corresponding author: J Wagner (drjaninewagner@gmail.com)

Background. Inadequately controlled labour pain is associated with numerous deleterious physiological and psychological effects. Epidural labour analgesia is accepted as the gold standard.

Objectives. To establish the frequency of labour epidural analgesia for vaginal and caesarean section delivery in Gauteng Province (GP) private and public hospitals.

Methods. GP maternity hospitals belonging to the three largest private hospital groups, and public academic, tertiary, regional and district maternity hospitals, were approached for inclusion in the study. A total of 24/47 private hospitals and 21/26 public hospitals agreed to participate in the present study and data from these hospitals were included in the data analysis. This was a retrospective study, and the delivery statistics and registers for 2015 were examined from all participating hospitals. Consecutive convenience sampling was applied.

Results. A total of 3560 labour epidurals were placed in the 45 participating hospitals in GP in 2015. About two-thirds (62\%; $n=2208)$ of these labour epidurals were placed in the private sector. The median (interquartile range (IQR)) annual epidural frequency for all participating private hospitals was 6\% (1.37 - 8.42). Only two public hospitals in GP were able to offer labour epidural services in 2015 and the annual proportion of deliveries with epidural placement was $4.1 \%$. Both hospitals were academic hospitals affiliated with a single university.

Conclusion. Similar to other developing countries, the labour epidural rates in GP hospitals were well below international labour epidural rates in 2015. This lack of service provision may be compromising patient care as well as the training of healthcare professionals.

Keywords. labour; epidural rate; Gauteng.

S Afr J Obstet Gynaecol 2020;26(3):Published online 24 May 2021. https://doi/org/10.7196/SAJOG.2020.v26i3.2006

Pain experienced during labour is a priority for most women, and most women in labour require analgesia. ${ }^{[1-3]}$ Labour analgesia is a basic human right, and the lack or unequal provision of an adequate analgesia service may be seen as a breach of the four ethical principles of autonomy, beneficence, non-maleficence and justice. ${ }^{[4]}$

Inadequately controlled labour pain is associated with numerous deleterious physiological and psychological maternal and fetal effects, including effects on labour progression, fetal outcome, maternal-fetal bonding, and successful breastfeeding. ${ }^{[5-7]}$

The provision of adequate labour analgesia has been found to be associated with higher levels of patient satisfaction. ${ }^{[8]}$ Patient satisfaction with labour is complex and multifactorial. Although there are numerous psychosocial factors that affect satisfaction, it is evident that higher levels of satisfaction are associated with better outcomes..$^{[9]}$

The lumbar epidural is regarded as the gold standard for intrapartum labour analgesia and its use is associated with numerous maternal, paternal, fetal and societal benefits including a reduction in paternal anxiety and stress; increased paternal involvement; participation and satisfaction with the childbirth experience; and a lower rate of maternal blood transfusions. ${ }^{[2,69,-11]}$ Although much controversy exists regarding the effect of labour epidural analgesia on delivery outcomes, there is evidence to suggest that the provision of labour epidural analgesia utilising low-dose techniques may be associated with a decrease in the rate of nonmedically indicated caesarean sections (CS), and a decrease in episiotomy rates. ${ }^{[9,10,12]}$

The provision of labour epidural analgesia has resulted in a change in focus from simple immediate pain relief to the overall quality of analgesia. ${ }^{[9]}$ The availability of labour epidural analgesia services is considered by some to be a reflection of the standard of obstetric care offered by a hospital. ${ }^{[9]}$ Labour epidural rates vary considerably between and within countries, and there is often wide inter-hospital variability. ${ }^{[13]}$

Labour epidural frequency is estimated to be between 40 and $60 \%$ in developed countries and $<10 \%$ in developing countries. ${ }^{[1,10,14-17]}$

Although there are a myriad of complex factors that affect service delivery and acceptance, provision of labour epidural analgesia in developing countries has been attributed to factors relating to health system disorganisation, inadequacies in communication, team work, maternal demographic characteristics and education, education of healthcare professionals, and misalignment of goals. ${ }^{[18]}$

There are no published data regarding labour epidural frequency in private hospitals in South Africa (SA). Data available from two isolated public hospital audits suggest that the epidural frequency in public hospitals is $<10 \%$, and may be as low as $2.5 \% .{ }^{[19-21]}$ 
The highest number of births ( $n=296$ 621) were registered in Gauteng Province (GP) in $2015,{ }^{[22]}$ and represented $27 \%$ of the registered births in SA at the time. [22] Given the high number of births in the province and the lack of information on the provision of labour epidurals, to our knowledge, we conducted the first multisite survey of labour epidural provision in the private and public sector hospitals in GP. We chose to conduct the present study in private and public hospitals because these systems exist in parallel, and great inequalities and inequities in access and use of public and private healthcare exist. ${ }^{[23]}$ It is essential to ascertain the current status of labour epidural provision in GP hospitals when aspiring towards international standards and health equity. Establishing a reference point will enable the evaluation of interventions initiated in the obstetric analgesia services.

\section{Methods}

This was a retrospective, contextual and descriptive study. A survey of hospital records and registers was undertaken to describe and compare the labour epidural frequency in GP public and private hospitals in 2015. All maternity hospitals operating in 2015 and belonging to the three largest private hospital groups ( $n=47)$, and the public academic, tertiary, regional and district maternity hospitals ( $n=26)$ were approached for inclusion. A list of the hospitals approached for inclusion in the present study is presented in Table 1.

Approval to conduct this study was obtained from the Human Research Ethics Committees (Medical) of the University of the Witwatersrand (ref. no. M150963) and the University of Pretoria (ref. no. 2/2016). Approval was also obtained from the Gauteng Department of Health (ref. no. GP2015RP53445). Written approval to conduct the research at each private hospital was obtained from each private hospital group.

All captured data evaluating hospital designation, total births, modes of delivery, epidural frequency and outcome of patients who received epidurals was recorded in a Microsoft Excel (Microsoft Corp.) spreadsheet.

Data were analysed using Statistica (version 13.2; Dell Technologies, USA) and $\mathrm{R}$ programming software (version 3.2.3; R Core Team, USA). Categorical data were summarised using frequencies and percentages. Continuous variables that were normally distributed were summarised using means and standard deviations (SDs), and those not normally distributed were summarised using medians and interquartile ranges (IQRs). Comparison between groups was done using $\chi^{2}$ tests. A $p$-value $<0.05$ was considered to be statistically significant.

\section{Results}

All public and private hospitals belonging to the three largest hospital groups were approached to participate in this present study. Managers at $n=24 / 47$ private hospitals and $n=21 / 26$ public hospitals agreed to participate, and data from these hospitals were included in the study. Public hospitals consisted of seven hospitals of each category - academic/ tertiary, regional and district. The breakdown of participants is shown in Fig. 1.

The majority of the private hospitals $(88 \% ; n=21 / 24)$ provided a labour epidural service, while only $10 \%(n=2 / 21)$ of the public sector hospitals provided such a service. The two public hospitals were academic/tertiary hospitals based in Johannesburg. There was a total of 174712 deliveries across 45 hospitals in GP in 2015. More than three-quarters of these deliveries (82\%; $n=143463$ ) were recorded in public hospitals. Monthly breakdown of the percentage and number of deliveries in public and private hospitals is provided in Fig. 2. There was very little variation in the number of deliveries in public and private hospitals in 2015.

A total of 3560 labour epidurals were placed in the 45 participating hospitals, but only $2 \%$ of all recorded deliveries had a labour epidural placed. The majority of these 3560 labour epidurals were placed in the private sector $(62 \%, n=2208)$ at a calculated monthly frequency of $7 \%$ (0 - 21\%; Fig. 3).

The number of labour epidurals placed in public hospitals was 1352 with a calculated monthly frequency of $0.9 \%$ (0 - 5.1\%; Fig. 3).

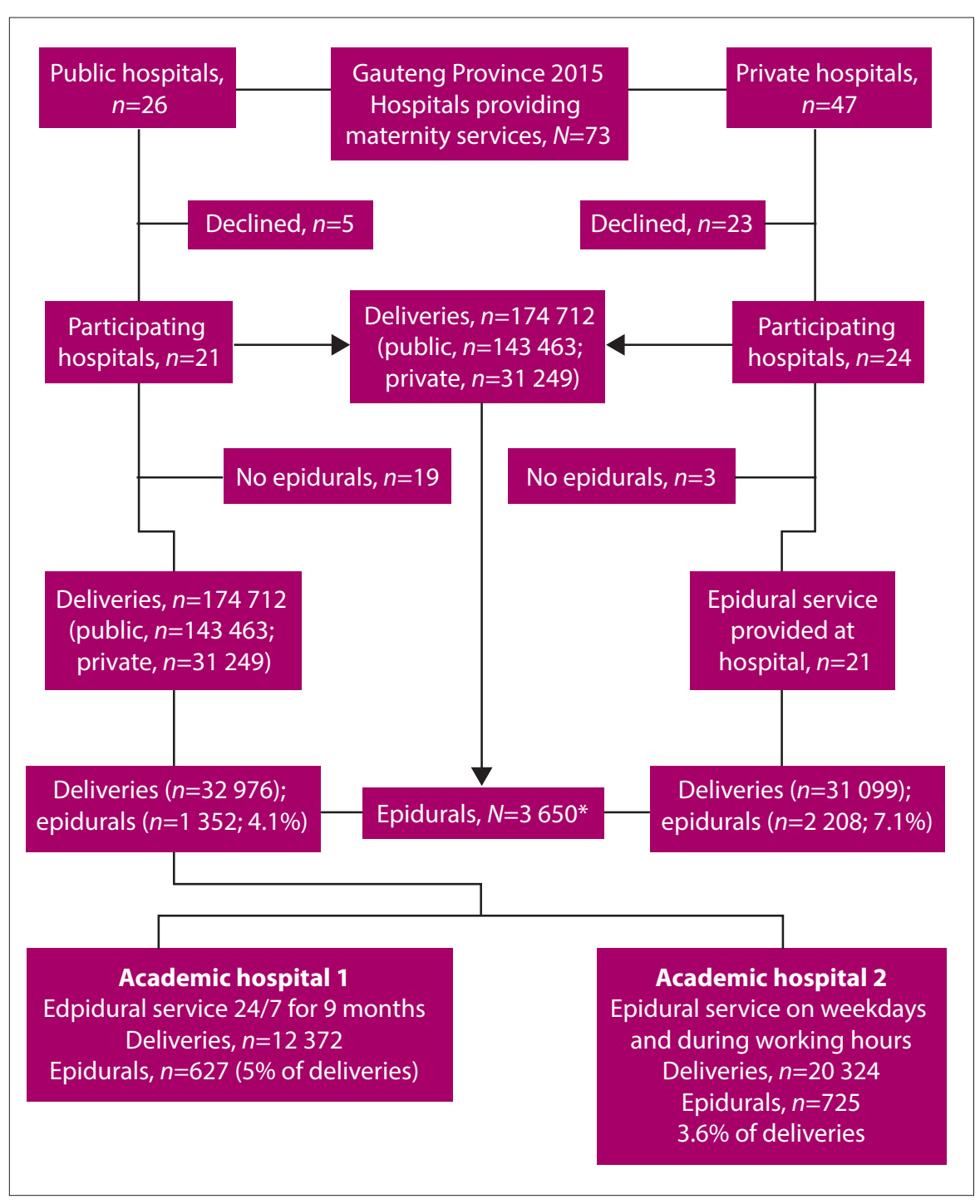

Fig. 1. Participant breakdown. ( ${ }^{\star} 2 \%$ of 174712 deliveries.) 
Table 1. List of hospitals approached for inclusion in the study Hospital

\section{Designation}

Netcare private

hospital group

\section{Hospital name}

Clinton Hospital, Garden City Hospital, Linmed

Hospital, Mulbarton Hospital, Olivedale Hospital, Parklane Hospital, Sunninghill Hospital,

Krugersdorp Hospital, Femina Hospital, Pretoria East Hospital, Unitas Hospital.

Mediclinic private Emfuleni, Kloof, Morningside, Muelmed,

hospital group

Life private

hospital group

Sandton, Vereeniging.

Brenthurst Clinic, Carstenhof Clinic, Eugene

Marais Hospital, Fourways Hospital, Robinson

Private Hospital, Roseacres Clinic, The

Glynnwood, Wilgeheuwel Hospital, Wilgers

Hospital, Suikerbosrand Hospital.

Academic and Chris Hani Baragwanath Academic Hospital,

tertiary public Charlotte Maxeke Johannesburg Academic

hospitals Hospital, Dr George Mukhari Hospital, Steve

Biko Academic Hospital, Rahima Moosa Mother and Child Hospital, Tembisa Hospital, Kalafong Hospital.

Regional public Edenvale Hospital, Leratong Hospital, Pholosong hospitals Hospital, Sebokeng Hospital, Tambo Memorial Hospital, Thelle Mogoerane Hospital, Far East Rand Hospital

District public Southrand Hospital, Bheki Mlangeni Hospital, hospitals Kopanong Hospital, Pretoria West Hospital, Jubilee Hospital, Odi Hospital, Carletonville Hospital

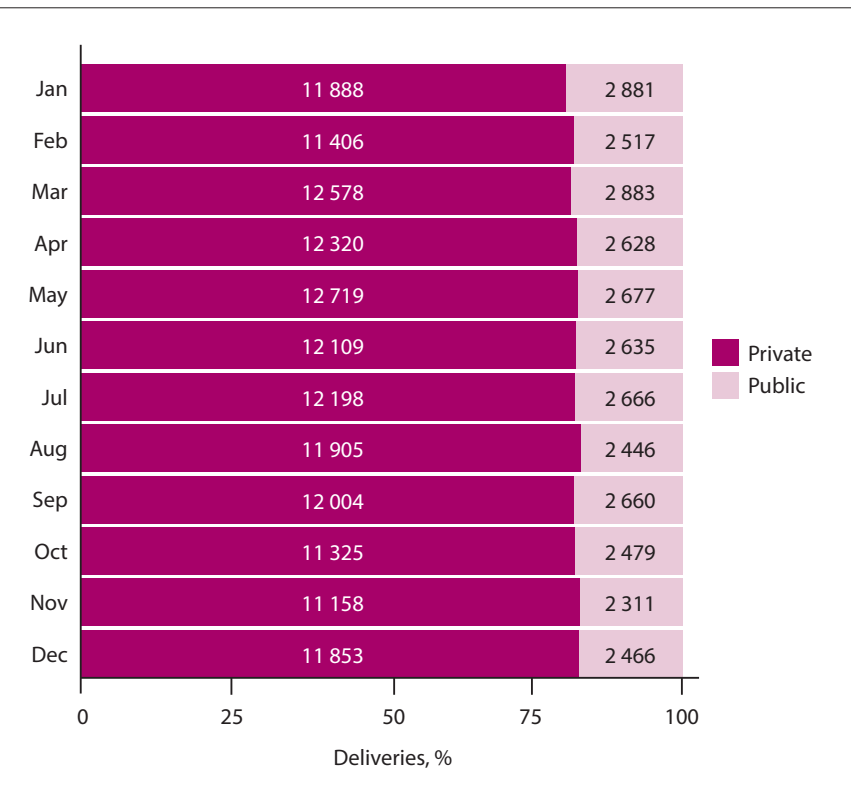

Fig. 2. Total monthly deliveries in participating hospitals in Gauteng Province.

The proportion of deliveries that had an epidural placement was significantly greater in the private hospitals compared with the public hospitals $\left(\chi^{2}=4\right.$ 802.2; $\left.\mathrm{df}=1 ; p<0.01\right)$. The annual proportion of deliveries with epidural placement was $4.1 \%$ in the two public hospitals that provided the service. However, only one of these two hospitals offered a labour epidural service that ran for 24 hours a day, seven days a week (implemented in April 2015) (Personal communication from Thomas Kleyenstuber, 16 January 2021). The proportion of deliveries with epidural placement was greater in that hospital compared with the hospital that had a

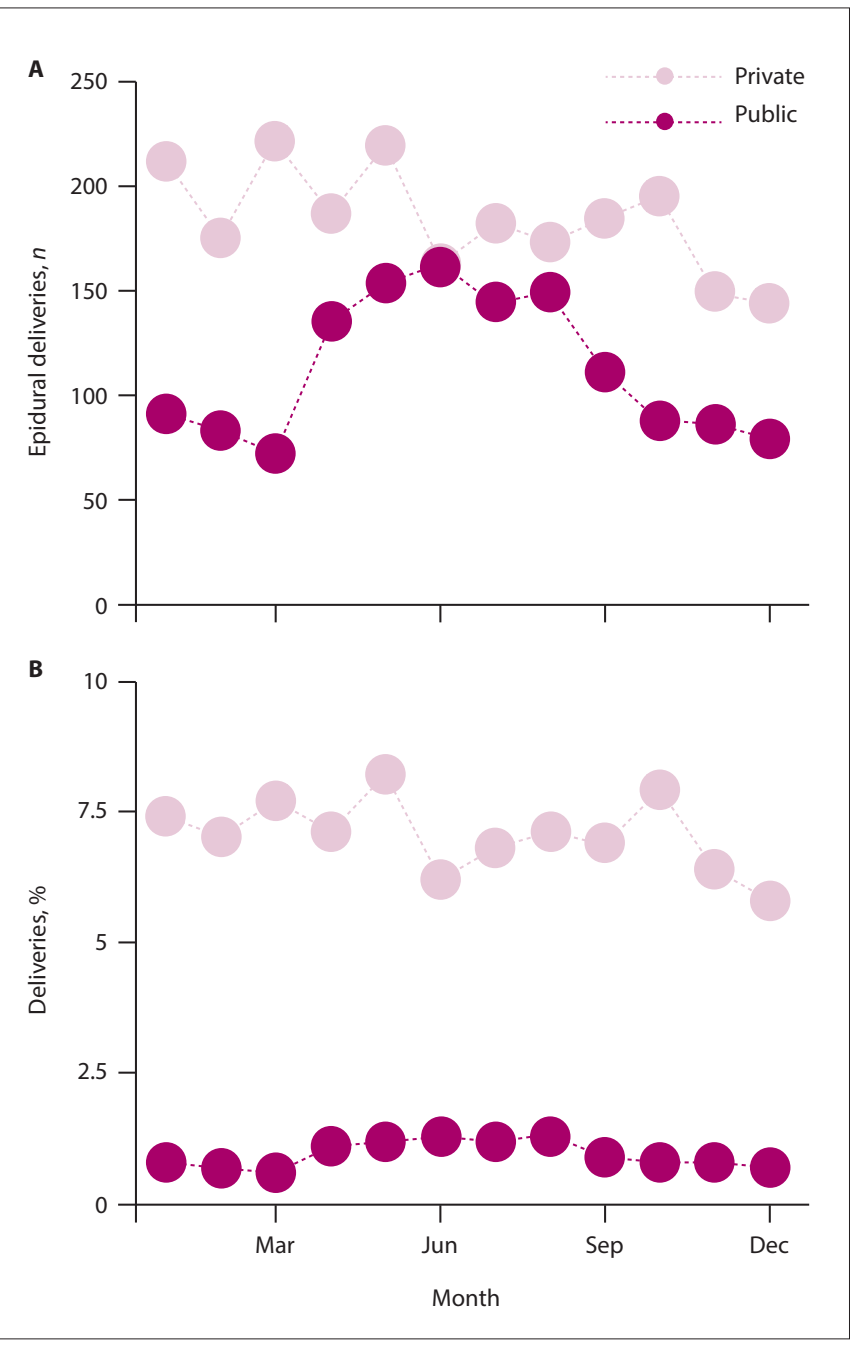

Fig. 3. Labour epidurals performed in private and public hospitals per month in Gauteng Province.

working hours only, weekdays only service $(5.1 \%$ of deliveries v. $3.6 \%$ of deliveries; $\chi^{2}=43.3 ; d f=1 ; p<0.01$ ).

The implementation of the 24 hours a day, 7 days a week labour epidural service in April 2015 at one Johannesburg public hospital was associated with more than doubling in the number of epidural placements from 72 ( $0.6 \%$ of deliveries in public hospitals) in March 2015 to 161 (1.3\% of deliveries in public hospitals) in June 2015. However, the use of the service fell to 79 cases $(0.8 \%$ of all deliveries in public hospitals) by December 2015 despite the service continuing to be offered.

There were three reports of failed attempts to insert labour epidurals in the private hospitals and 20 reports in the public hospitals, 15 of which were from a single tertiary academic hospital. The failed insertion rate for labour epidurals was $0.6 \%(0.14 \%$ in private and $1.45 \%$ in public hospitals) in GP in 2015.

More than a third (43\%; $n=75040)$ of deliveries in the participating hospitals were by CS. In private hospitals, $76 \%$ ( $n=23$ 824/31 249) of the deliveries were by CS while $36 \%$ ( $n=51216 / 143463$ ) were by CS in the public hospitals. There was a significant difference between the proportion of CS births in private and public hospitals $\left(\chi^{2}=17209\right.$; $d f=1 ; p<0.01)$.

In the hospitals that provided labour epidural analgesia, the frequency of women who received epidural analgesia for vaginal delivery, which eventuated in a conversion to a CS, was $3 \%$ 


\section{RESEARCH}

Table 2. Method of anaesthesia for caesarean section in patients who received labour epidurals

\begin{tabular}{llll}
\hline Hospital & $\begin{array}{l}\text { Epidural } \\
\text { top-up, } \boldsymbol{n}(\%)\end{array}$ & $\begin{array}{l}\text { Spinal } \\
\text { anaesthetic, } \boldsymbol{n}(\%)\end{array}$ & $\begin{array}{l}\text { General } \\
\text { anaesthetic, } \boldsymbol{n}(\%)\end{array}$ \\
\hline Private & $396(76)$ & $104(20)$ & $13(3)$ \\
Public & $176(36)$ & $239(49)$ & $65(13)$ \\
$x^{2}=163.01, d f=2, p<0.01$. & &
\end{tabular}

( $n=1013 / 35098), 2 \%(n=523 / 22834)$ for private hospitals and $4 \%$ ( $n=490 / 12$ 264) for public hospitals. The methods used to provide anaesthesia for CS to patients who had received labour epidurals are shown in Table 2.

More than three-quarters (76\%) of the labour epidurals in the private hospitals were topped up and used to provide anaesthesia for CS compared with $36 \%$ in the public hospitals. There was a significant difference in the methods of anaesthesia (Table 2) that were used for patients who underwent CS in whom labour epidurals were placed in private and public hospitals $\left(\chi^{2}=163.01\right.$; $d f=2 ; p<0.01$ ).

There are numerous factors that affect the decision regarding selection of an anaesthetic modality for a parturient undergoing CS delivery. However, choice selection is known to be affected by patient characteristics including socioeconomic status and level of maternal education as well as the knowledge, experience and expertise of anaesthetists and obstetricians. ${ }^{[24]}$

When recalculating the proportion of deliveries using labour epidurals after excluding the number of deliveries performed by CS (and excluding CS performed under epidural anaesthesia), the epidural frequency was $3.29 \%(n=3560 / 108$ 231) for vaginal deliveries, $13.81 \%$ in private hospitals and $1.47 \%$ in public hospitals.

There were a total of 2924 assisted deliveries in the participating GP hospitals. The majority of these assisted deliveries $(62 \% ; n=1801)$ were performed in private hospitals and $81 \%(n=909)$ of the assisted deliveries performed in public hospitals were performed in participating tertiary/academic hospitals. There was a significant difference in the assisted delivery rate in participating public and private hospitals $\left(\chi^{2}=2079 ; \chi^{2}=1 ; p<0.0001\right)$.

Of the patients who received labour epidurals, more than threequarters (76\%; $n=1682$ ) of patients who received labour epidurals in private hospitals delivered vaginally, while $52 \%(n=707)$ of the patients delivered vaginally in public hospitals $\left(\chi^{2}=219.34 ; d f=1\right.$; $p<0.001)$. There was a significant association between having a labour epidural and needing a CS in private hospitals $\left(\chi^{2}=3612.4\right.$; $d f=1 ; p<0.0$; odds ratio (OR) 0.08 ; $95 \%$ confidence interval (CI) $0.07-0.08)$, but not in public hospitals, $\left(\chi^{2}=0.97 ; d f=1 ; p=0.33\right.$; OR $0.94 ; 95 \%$ CI $0.8-1.1)$. The odds of needing a CS in private patients with labour epidurals was $8 \%$ less than those who do not receive labour epidurals. There was a significant difference in the indications for CS in private and public patients where labour epidurals were placed (Fig. 4).

The percentage of patients who received labour epidurals and delivered vaginally with assistance in private and public hospitals was $33 \%(n=728)$ and $3 \%(n=44)$, respectively. There was a significant difference in the number of assisted deliveries and the assisted delivery rates in patients who had received labour epidurals in private compared with public hospitals $\left(\chi^{2}=313.33 ; d f=1\right.$;

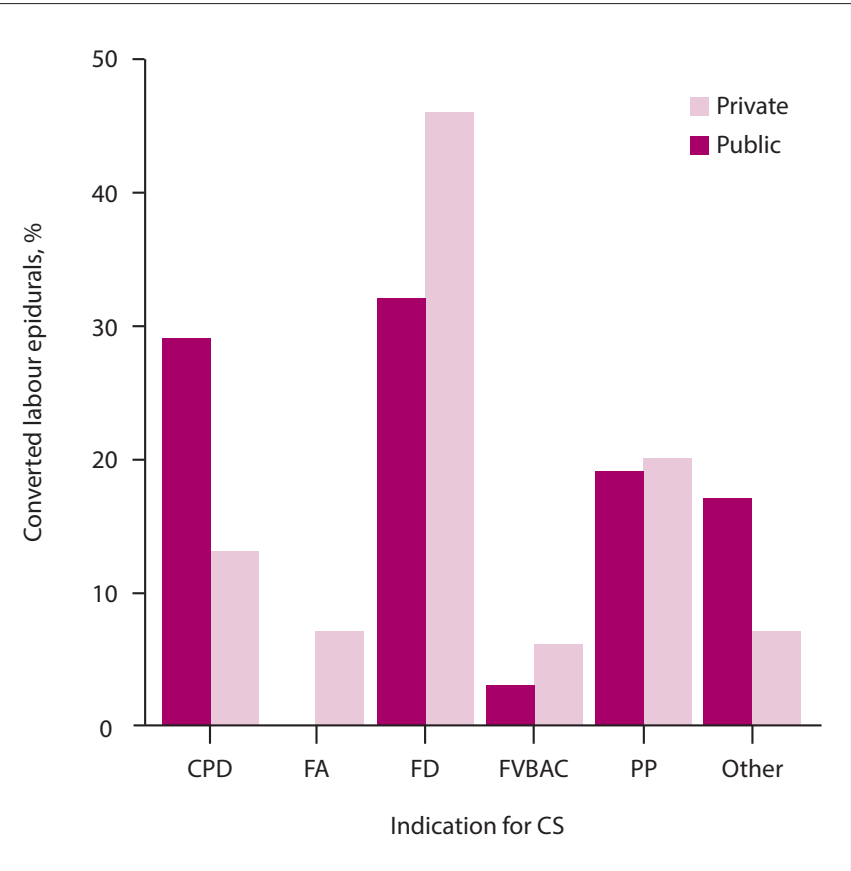

Fig. 4. Indications for caesarean section in patients receiving labour epidurals. $(C P D=$ cephalopelvic disproportion; $F A=$ failed augmentation; $F D=$ fetal distress; $F V B A C=$ failed vaginal birth after caesarean section; $P P=$ poor progress.)

$p<0.001)$. Moreover, there was a significant association between receiving an epidural and vaginal delivery with assistance in private $\left(\chi^{2}=3.3 ; d f=1 ; p<0.001\right)$ and public hospitals $\left(\chi^{2}=32.15 ; d f=1\right.$; $p<0.001)$. The odds of a patient with an epidural delivering vaginally with assistance in private hospitals was 13 times greater (OR 12.89; $95 \%$ CI $11.56-14.48)$ than if the patient delivered vaginally without an epidural, whereas in public hospitals the odds were 2.4 times greater (OR 2.41; 95\% CI 1.72 - 3.32).

\section{Discussion}

In line with other developing countries, the labour epidural rates were well below internationally cited labour epidural rates in GP hospitals in $2015 .^{[1,10,14-17]}$ Very few public training hospitals offered labour epidural services, but the epidural rates in public hospitals in GP were similar to those in public hospitals in Western Cape Province. ${ }^{[19-20]}$ This may be a result of similar limitations in service delivery in most public maternity hospitals, but further research is needed to determine this. The epidural rates were higher in public hospitals in 2015 than those reported in a study conducted by Leonard et al. ${ }^{[21]}$ This is most likely a result of the initiation of a 24/7 labour epidural service in 2015 at the same GP academic hospital initially evaluated by Leonard et al. ${ }^{[21]}$ in 2014.

Factors limiting the provision and uptake of labour epidural services in SA have not been fully elucidated. ${ }^{[20]}$ However, insufficient knowledge, poor awareness and inadequate exposure of healthcare workers to the analgesic modality during their academic training may be contributing factors to poor rates in both the public and private sector and requires further study. ${ }^{[18]}$

CS rates in GP private and public hospitals in 2015 were higher than the CS rates of $10-15 \%$ recommended by the WHO. ${ }^{[25]}$ A similar finding to that described in GP private hospitals was observed in a study conducted by Hu et al. ${ }^{[10,25]}$ in China, where the majority of CS were conducted electively. 
Similarly to the study conducted by $\mathrm{Hu}$ et al., ${ }^{[25]}$ the lack of readily available labour epidural analgesia services in GP may be affecting patient delivery preferences. This may be contributing to high CS rates and an increase in non-medically indicated CS. ${ }^{[10]}$ High rates of nonmedically indicated CS may have a negative effect on the economy, health equity and the establishment of National Health Insurance (NHI) in SA in the future.

We observed a significant association between receiving a labour epidural and needing an assisted delivery in private and public patients $(p<0.01)$, similarly to the findings of the Cochrane review published in 2011. ${ }^{[2]}$ However, in the present study, the OR for private patients (OR 12.89; 95\% CI $11.56-14.48)$ was $\sim 4$ times greater than the OR for public patients (OR 2.41; 95\% CI 1.72 - 3.32).

Further research is needed to determine why assisted delivery rates differ. The differences in delivery outcomes may be explained by differing anaesthetic practices in private and public hospitals, the concentrations of local anaesthetics used, and under-reporting of assisted deliveries. Lack of equipment needed to perform assisted deliveries in public hospitals may also be a contributing factor. ${ }^{[27]}$

Fetal distress is a common indication for CS in women who receive labour epidurals. ${ }^{[29,30]}$ The association between labour epidural analgesia and maternal fever is complex and controversial, but it is believed that up to $20 \%$ of parturients receiving labour epidural analgesia may develop a fever that may be associated with fetal tachycardia and fetal distress. ${ }^{[2,30]}$ Inadequate maternal temperature monitoring and poor management of maternal pyrexia may contribute to the number of patients undergoing CS or requiring assisted deliveries. ${ }^{[28,30]}$ Further urgent research is needed to confirm this as inadequate management of maternal fever has been linked with transient and long-term adverse neonatal developmental outcomes including low Apgar scores, respiratory distress, hypotonia, neonatal seizures, encephalopathy, cerebral palsy and neonatal death. ${ }^{[29]}$

Epidural insertion failure rates were found to be lower than rates reported in the literature, but are most likely a result of underreporting, low epidural rates and the lack of adoption of a standard definition for labour epidural failure. Adoption of a standard definition is essential and recommended to enable the evaluation and auditing of services.

\section{Study limitations}

The study is limited by its contextual nature in that the population was limited to participating private maternity hospitals belonging to the three largest private hospital groups, and the participating academic, tertiary, regional and district public hospitals in GP. The results therefore may not be generalised to all hospitals in GP or all hospitals in SA.

The use of multiple sources to obtain the data were a limitation. The source of provided hospital statistics, the quality of information available from the delivery registers and delivery records, and the availability of delivery records could have compromised data quality.

The lack of standardisation of definitions for births and deliveries between hospitals and the definition of delivery and birth for the present study may have differed and thus could have been a limitation.

According to the definitions used in the present study, the statistics provided by the hospitals for deliveries may have been for births and not deliveries, and thus would have resulted in an over-estimation of the deliveries that occurred at the hospital and an under-estimation of the rate calculated based on the delivery numbers. However, the effect of this would have been negligible as the incidence of multiple pregnancies is $\sim 1 \%$ and $\sim 11 \%$ for stillbirths, which are considered to be low. ${ }^{[2,32]}$

\section{Conclusion}

Labour epidural and vaginal delivery rates were below internationally cited and recommended rates in GP hospitals. Very few public training hospitals were found to offer labour epidural services. The lack of service provision may be compromising the training of healthcare professionals in GP, and may in turn be affecting service delivery in private hospitals. However, epidural failure rates were found to be extremely low.

Mechanisms to initiate, improve and sustain labour epidural services should be urgently investigated and adopted. The adoption of a standard definition for epidural failure and implementation of mechanisms for reporting epidural failures are recommended.

Further studies are recommended to determine the effect of increasing the provision of labour epidural services on rates of nonmedically indicated CS, to determine the limitations to the provision of labour epidural services, and to determine the effect of lack of service provision on the knowledge of healthcare professionals.

\section{Declaration. None.}

Acknowledgements. We would like to send special thanks to Netcare, Mediclinic and Life hospital groups.

Author contributions. JW conceptualised the study, conducted the data analysis with the assistance of PK and wrote the draft of the manuscript. All authors contributed in the editing and approval of final manuscript for publication.

Funding. JW was funded by the SASA Jan Pretorius Fund and Carnegie Corporation of New York (grant number B8749.R01).

Conflicts of interest. None.

1. Torri, A. The role of social, economic and religious factors in the availability of neuraxial labour analgesia worldwide. Curr Aneasthesiol Rep 2013;3(4):250-255. https://doi.org/10.1007/s40140013-0037-2

2. Jones L, Othman M, Dowswell $\mathrm{T}$ et al. Pain management for women in labour: An Jones L, Othman $M$, Dowswell $T$ et al. Pain management for women in labour: An
overview of systematic reviews. Cochrane Database Syst Rev 2012;3:CD009234. https://doi. overview of systematic reviews. Coch
org/10.1002/14651858.CD009234.pub2

3. Findley I, Chamberlain CG. ABC of labour care. Relief of pain. Br Med J 1999:318(7188):927-930. https://doi.org/10.1136/.318.7188.927

4. Brennan F, Carr DB, Cousins M. Pain management: A fundamental human right. Anaesth Analg 2007;105(1):205-221. https://doi.org/10.1213/01.ane.0000268145.52345.55

5. Population Reference Bureau. Hidden suffering: Disabilities from pregnancy and childbirth in less developed countries. 2002. http://www.prb.org/Publications/Reports/2002/ HiddenSufferingDisabilitiesFromPregnancyandChildbirthinLDCs.aspx (accessed 21 June 2017).

6. Anim-Somuah M, Smyth RM, Cyna AM, Cuthbert A. Epidural vs non-epidural or no analgesia for pain management in labour. Cochrane Datab Syst Rev 2018;5:CD000331. https://doi. org/10.1002/14651858.CD000331

7. Kannan, S, Jamison RN, Datta S. Maternal satisfaction and pain control in women electing natural childbirth. Reg Anaesth Pain Med 2001;26(5):468-472. https://doi.org/10.1053/rapm.2001.24260

8. Xesfingi S, Vozikis A. Patient satisfaction with the healthcare system: Assessing the impact of socioeconomic and healthcare provision factors. BMC Health Services Res 2016;16:94-100. https://doi. org/10.1186/s12913-016-1327-4

9. Pandya ST. Labour analgesia: Recent advances. Indian J Anaesth 2010;54(5):400-408. https://doi. org/10.4103/0019-5049.71033

10. Hu LQ, Zhang J, Wong CA, et al. Impact of the introduction of neuraxial labour analgesia on mode of delivery at an urban maternity hospital in China. Int J Gynaecol Obstet 2015;129(1):17-21. https://doi.org/10.1016/j.ijgo.2014.10.030

11. Capogna G, Camorcia M, Stirparo S. Expectant fathers' experience during labour with or without epidural analgesia. Int J Obstet Anaesth 2007;16(2):110-115. https://doi.org/10.1016/j. ijoa.2006.08.009

12. Goer H. Epidurals: Do they or don't they increase caesareans? J Perinat Educ 2015;24(4):209-212. https://doi.org/10.1891/1058-1243.24.4.209

13. Ginosar Y, Ioscovich A, Weissman C, Calderon-Margalit R, Weiniger CF. Comparison of the obstetric anaesthesia activity index with total delivery numbers as a single denominator of workload demand in Israeli maternity units. Isr J Health Policy Res 2012;1(1):48. https://doi. org/10.1186/2045-4015-1-48

14. Chigbu CO, Onyeka TC. Denial of pain relief during labor to parturients in southeast Nigeria. Int J Gynaecol Obstet 2011;114(3):226-228. https://doi.org/10.1016/j.ijgo.2011.04.006

15. Osterman MJ, Martin JA. Epidural and spinal anaesthesia use during labour: 27-state reporting area, 2008. Natl Vital Stat Rep 2011;59(5):1-16. 


\section{RESEARCH}

16. Canadian Institute for Health Information. Highlights of 2010-2011 selected indicators describing the birthing process in Canada. Ottawa: CIHI, 2013, https://secure cihica/free products/ Childbirth_Highlights 2010-11_EN.pdf (accessed 1 July 2015).

17. Alran S, Sibony O, Oury JF, Luton D, Blot P. Differences in management and results in termdelivery in nine European referral hospitals: Descriptive study. Eur J Obstet and Gynaecol Reprod Biol 2002;103(1):4-13. https://doi.org/10.1016/S0301-2115(02)00028-3

18. Kintu A, MacCormick H, George RB. Establishing an epidural service for labour analgesia in a variable resource environment. Update Anaesth 2019;34:35-40. https://doi.org/10.1029/ WFSA-D-18-00022

19. Jacobs-Martin GG, Burke JL, Levin AI, Coetzee AR. Labour epidural analgesia audit in a tertiar state hospital in South Africa. S Afr J Anaest Analg 2014;20(4):174-178. https://doi.org/10.1080/ 22201181.2015.95934

20. van Zyl SF, Burke JL. Increasing the labour epidural rate in a state hospital in South Africa: Challenges and opportunities. S Afr J Anaest Analg 2017;23(6):156-161. https://doi.org/10.1080 /22201181.2017.1401773

21. Leonard TG, Perrie H, Scribante J, Chetty S. An audit of the labour epidural analgesia service at a regional hospital in Gauteng Province, South Africa. S Afr J Obstet Gynaecol 2018;24(2):52-56. https://doi.org/10.7196/sajog.1314

22. Statistics South Africa. Statistical release P0305. Recorded live births 2013-2015. Pretoria: StatsSA 2016. http://www.statssa.gov.za/publications/P0305/P03052015.pdf (accessed 23 April 2019).

23. Ranchod S, Adams C, Burger R et al. South Africa's hospital sector: Old divisions and new developments. SAHR 20-year anniversary edition. 2017. https://www.researchgate.net/ publication/319236440_South_Africa’s_hospital_sector_old_divisions_and_new_developments link/5ae2dc33a6fdcc9139a103dd/download (accessed 23 April 2019).
24. Arslan B, Ozturk NK, Onuk ZA, Karsli B. Factors affecting selection of anaesthesia type in elective caesarean operations and pregnant preferences for anaesthesia outcome. Med Sci 2018;8(1):113-116. https://doi.org/10.5455/medscience.2018.07.8924

25. Department of Reproductive Health and Research, World Health Organization. WHO statement on caesarean section rates. WHO/RHR/15.02. Geneva: WHO, 2015. https://apps.who.int/iris/bitstream/ handle/10665/161442/WHO_RHR_15.02_eng.pdf (accessed 25 April 2019).

26. Hu L, Flood P, Li Y, et al. No pain labour \& delivery: A global health initiative's impact on clinical outcomes in China. Anaesth Analg 2016;122(6):1931-1938. https://doi.org/10.1213/ANE.0000000000001328

27. Ameh CA, Weeks AD. The role of instrumental vaginal delivery in low resource settings. BJOG 2009;116(1):22-25. https://doi.org/10.1111/j.1471-0528.2009.02331.x

28. Burgess AP, Katz JE, Moretti M, Lakhi N. Risk factors for intrapartum fever in term gestations and associated maternal and neonatal sequelae. Gynaecol Obstet Invest 2017;82(5):508-516. https://do org/10.1159/00045361

29. Mercier FJ, Benhamou D. Hyperthermia related to epidural analgesia during labour. Int J Obstet Anaesth 1997;6(1):19-24. https://doi.org/10.1016/50959-289X(97)80047-7

30. Katherine W, Arendt KW, Segal BS. The association between epidural labour analgesia and maternal fever. Clin Perinatol 2013;40(3):385-398. https://doi.org/10.1016/j.clp.2013.06.002

31. Statistics South Africa. Perinatal deaths in South Africa 2015, Statistical release P0309.4. Pretoria: StatsSA 2017. http://www.statssa.gov.za/publications/P03094/P030942015.pdf (accessed 7 November 2019).

Accepted 6 April 2021 